\title{
Design of a sustainable polygeneration microgrid for the retrofitting of an industrial site: Ansaldo Energia case study
}

\author{
Enrico Bianchi ${ }^{1}$, Stefano Bracco ${ }^{2}$, Fabio Cannizzaro $^{2}$, Federico Delfino ${ }^{2}$, and Alessandro \\ Giacchino $^{3}$ \\ ${ }^{1}$ Ansaldo Energia Spa, Microturbine Division, Via N. Lorenzi 8, 16152 Genoa, Italy \\ ${ }^{2}$ University of Genoa, DITEN - Department of Naval, Electrical, Electronic and Telecommunication \\ Engineering, Via all'Opera Pia 11a, 16145 Genoa, Italy \\ ${ }^{3}$ Ansaldo Energia Spa, Power Plant System Engineering, Via N. Lorenzi 8, 16152 Genoa, Italy
}

\begin{abstract}
The aim of this paper is that of proposing a methodology on how to design a microgrid for an industrial area. In particular, the paper reports the description of a project, jointly developed by the University of Genoa and Ansaldo Energia SpA, to design a polygeneration microgrid for the industrial site of Ansaldo Energia company in the Metropolitan City of Genoa. The microgrid infrastructure integrates different technologies to satisfy the electrical, thermal and cooling demand of the site, among which an important role is played by the cogeneration AE T100 microturbines developed by the company. In the paper, the optimization tool AEN-MGD, developed to optimally design and operate the microgrid, is described and different possible configurations of the microgrid are investigated and analysed from the technical, economic and environmental point of view. The proposed model has a general validity and it can be used to design and operate other similar energy infrastructures.
\end{abstract}

\section{Introduction}

The European and the Italian energy strategies aim at reducing primary energy consumptions and carbon dioxide emissions in different sectors such as the industrial and the residential ones [1]. In particular, in industries energy efficiency measures have to be implemented in order to reduce the energy bill and to make industrial processes and work places respectively sustainable and more livable. Different solutions can be adopted to improve the quality of energy supplies by exploiting renewable energy sources and high efficiency generation units. In the aforesaid context, [2-9] show the diffusion of sustainable microgrids operated by Energy Management Systems which minimize operating costs and/or emissions. In particular, in $[2,6,10]$ mathematical models used to optimally design and manage microgrids are reported, whereas in $[3,4]$ the main technologies adopted in microgrids are investigated.

In the present paper, a methodology to optimally design a sustainable microgrid within an industrial site is proposed and the attention is focused on a real test case represented by the Ansaldo Energia site located in Genoa, in the North of Italy. The goal of 
the developed project is that of defining a hybrid system for the production of electrical, thermal and cooling energy which is able to satisfy the energy needs of the factory. The attention is pointed on cogeneration and trigeneration technologies, renewable power plants and storage systems. The present paper is organized as follows. In Section 2 the description of the case study is reported, in Section 3 the Mixed-Integer Linear Programming (MILP) model, called AEN-MGD and developed to design and operate a microgrid, is described whereas in Section 4 the main results obtained by applying the AEN-MGD to the case study are proposed, together with the investment profitability analysis and the $\mathrm{CO}_{2}$ emission reduction evaluation. In Section 5, a sensitivity analysis on economic indicators is carried out and in Section 6 conclusions are outlined.

\section{Ansaldo Energia case study}

As is highlighted in Fig. 1, Ansaldo Energia site in Genoa is divided into four areas: Campi 1, Campi 2, Fegino and Boschetto. Each of them is characterized by its own electrical and thermal energy demand, the latter being mainly due to heating and Domestic Hot Water (DHW) requests. The factory is connected to the medium voltage distribution public grid, as shown in Fig. 2 where the electrical on-line diagram of the site is reported.

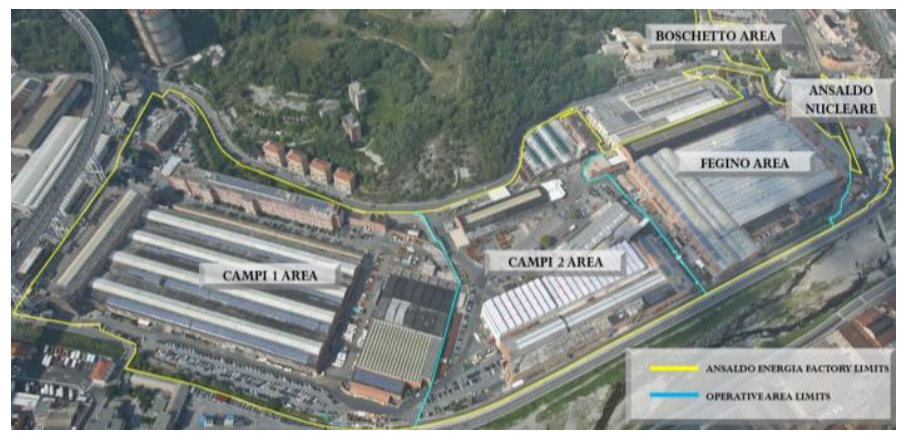

Fig. 1. Aerial view of Ansaldo Energia site in Genoa.

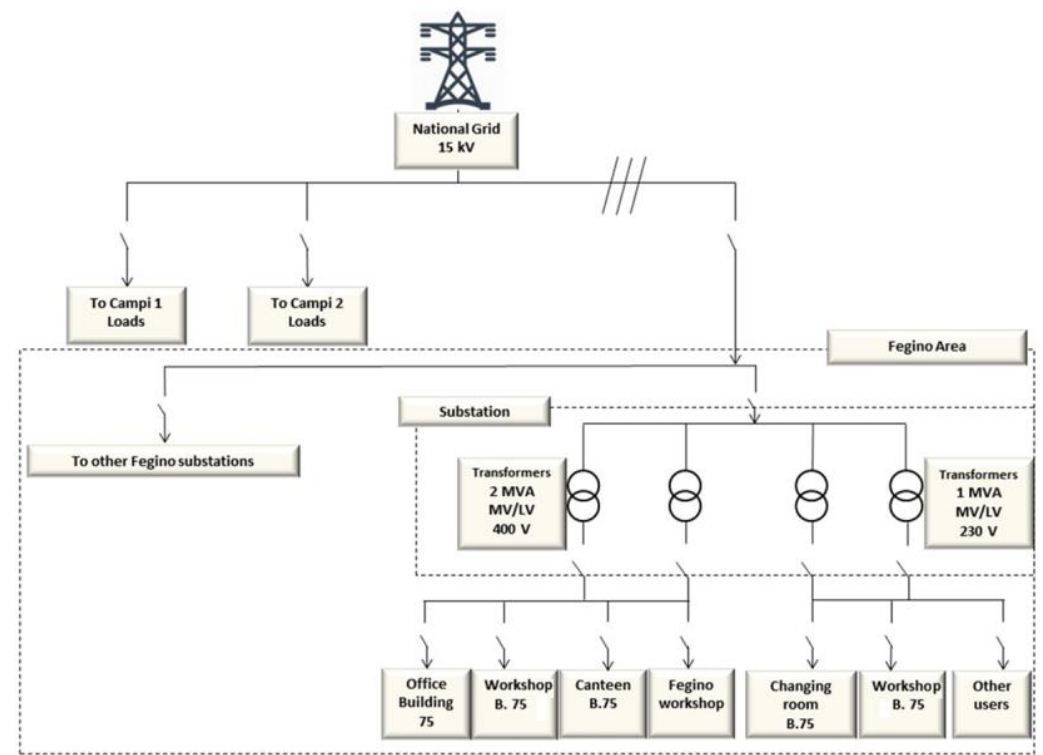


Fig. 2. Electrical one-line diagram of Ansaldo Energia site.

In order to supply thermal energy, an internal District Heating Network (DHN), fed by the Sampierdarena external DHN, is used. In particular, as shown in Fig. 3, there is a main thermal station where heat transfer between the external and the internal DHN occurs through three heat exchangers from which heating pipelines are conveyed to the different areas of the site. The project has initially focused the attention on Fegino area that has been considered suitable for the installation of a microgrid for many reasons: the numerous users (different in terms of load profiles) belonging to the building B.75 and to the Fegino workshop, currently supplied by the B.76 thermal sub-station; the proximity of B.76 to the Fegino electrical substation which shall bring a reduction of costs in terms of electric connection of the microgrid; the decision of the company to retrofit B.76 by removing two outdated and unused gas boilers.

Data acquisition software tools provided by the company have been used to analyze energy consumption data and to determine the load profiles of the site. The data analysis aimed to identify the users for which cogeneration can be considered favorable and to define the input data for AEN-MGD tool. Firstly, typical days which represent a week have been chosen: one weekday, one Saturday and one Sunday. Then, typical weeks representing each season have been selected, as reported in Tab.1. In particular, taking into account the on/off periods of heating and cooling systems, 21 typical days ( 3 for each season) have been assumed to represent the annual operation of the site.

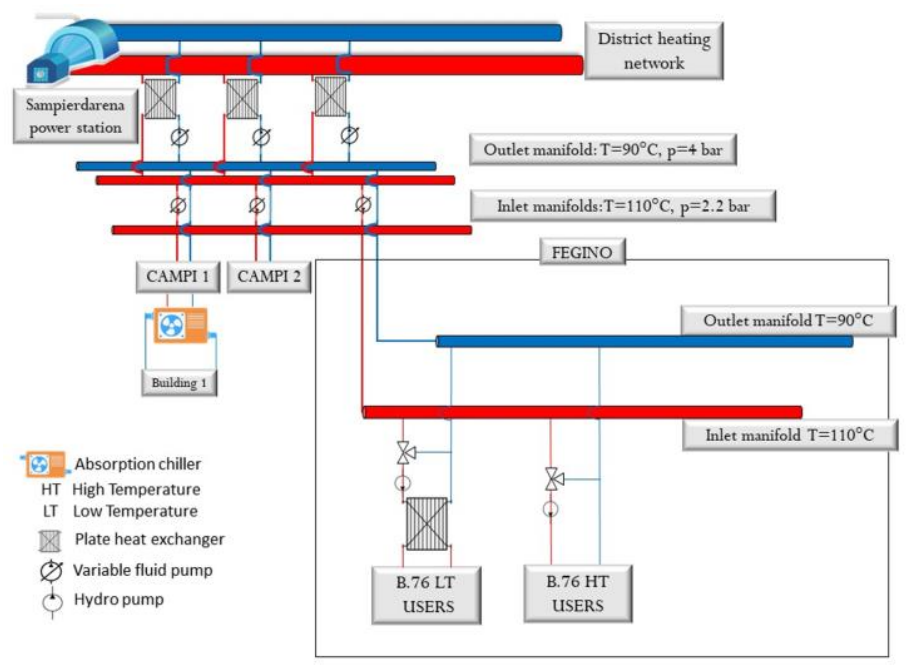

Fig. 3. Ansaldo Energia DHN diagram focused on Fegino area.

Table 1. Definition of typical seasons for load profile evaluation.

\begin{tabular}{|c|c|c|c|c|}
\hline Seasons & Months & Heating system & $\begin{array}{c}\text { Cooling } \\
\text { system }\end{array}$ & $\begin{array}{c}\text { Average ambient } \\
\text { temperature }\left[{ }^{\circ} \mathbf{C}\right]\end{array}$ \\
\hline Warm winter & November, March & ON & OFF & 15 \\
\hline Cold winter & January, February, December & ON & OFF & 10 \\
\hline Cold spring & First half April & ON & OFF & 15 \\
\hline Warm spring & Second half April, May & OFF & ON & 20 \\
\hline Summer & June, July, August & OFF & ON & 30 \\
\hline Warm autumn & First half September & OFF & ON & 20 \\
\hline Cold autumn & Second half September, October & OFF & OFF & 18 \\
\hline
\end{tabular}




\section{The AEN-MGD optimization tool}

The AEN-MGD tool is based on a MILP model, developed in the Matlab environment using Yalmip toolbox, which aims to optimally design and operate an electrical/thermal/cooling microgrid where the following technologies have been considered for the possible installation: photovoltaic panels (PV), cogeneration microturbines (GT), specifically of AE-T100 type, absorption chillers (AC), and electrical storage batteries (ES). The main outputs provided by AEN-MGD are: the size and the number of installed technologies; the generation profiles of power plants; the charging and discharging profiles of batteries; the power exchanged between the microgrid and the national grid; the thermal energy exchanged between the microgrid and the factory internal DHN.

For the sake of brevity, in the following only the main data, decision variables and constraints of the MILP problem are reported. Data are composed of: time parameters $(\mathrm{T}$ number of time intervals into which each day is subdivided, D - number of typical days, etc.); energy loads; economic data (capital and maintenance costs of technologies, electricity selling and purchase unit prices, natural gas price, etc. [11-13]); technical data (AE-T100 performances curves, solar radiation on PV panels, maximum and minimum number of PV panels and batteries which can be installed, battery charging/discharging efficiency, etc.). Decision variables are mainly related to: PV (number of installed panels and power generated); Grid (electric power withdrawn/injected from/into the national grid); ES (number of installed batteries, state of charge, charged/discharged power); AE T100s (number of installed microturbines, thermal and electrical power production, primary power consumption); AC (number of installed absorption chillers, cooling power production and thermal consumption); DHN (thermal power withdrawn from the factory internal DHN to satisfy thermal and cooling load demand).

The electrical balance of the microgrid can be written (for each time interval $t$ of $d$ day) as:

$$
W_{t, d}^{s}+D_{t, d}^{\mathrm{el}}+W_{t, d}^{\mathrm{ES} \_ \text {in }}=W_{t, d}^{\mathrm{PV}}+W_{t, d}^{\mathrm{b}}+W_{t, d}^{\mathrm{ES} \_ \text {out }}+\sum_{k} W_{k, t, d}^{\mathrm{GT}}
$$

where $W$ and $D$ terms respectively indicate the power released (PV, ES_out, GT, s=sold) or absorbed (ES_in, b=bought) by the microgrid and the whole electrical load. On the other hand, the thermal balance for the seasons when the heating system is on can be expressed as:

$$
D_{t, d}^{\mathrm{th}}=\sum_{k} U_{k, t, d}^{\mathrm{GT} \mathrm{TD}_{k}}+U_{t, d}^{\mathrm{DHN} \_\mathrm{TD}}
$$

which indicates that the whole thermal load $\left(D^{t h}\right)$ is equal to the sum between the thermal power provided by the microturbines $\left(U^{G T_{-} T D}\right)$ and that withdrawn from the internal DHN $\left(U^{D H N_{-} T D}\right)$. For the other seasons, when thermal load is lower, the constraint (2) becomes an inequality in order to permit the operation of microturbines also in no-cogeneration mode. Finally, the thermal power required by the absorption chillers $\left(U^{A C}\right)$ can be provided from both the microturbines and the internal DHN as follows:

$$
\sum_{h} U_{h, t, d}^{\mathrm{AC}}=\sum_{k} U_{k, t, d}^{\mathrm{GT} \_\mathrm{CD}}+U_{t, d}^{\mathrm{DHN} \_\mathrm{CD}}
$$

As a consequence, for each $k$-th microturbine the following equality occurs: 


$$
U_{k, t, d}^{\mathrm{GT} \_\mathrm{TD}}+U_{k, t, d}^{\mathrm{GT} \_\mathrm{CD}}=U_{k, t, d}^{\mathrm{GT}}
$$

and the total thermal power $U^{G T}$ provided by the microturbine is related to the produced electrical power $W^{G T}$ by means of a linear performance curve:

$$
U_{k, t, d}^{\mathrm{GT}}=\lambda_{d} \cdot W_{k, t, d}^{\mathrm{GT}}+\tau_{d} \cdot X_{k, t, d}^{\mathrm{GT}}
$$

where $\lambda$ and $\tau$ are coefficient dependent on ambient operating conditions whereas $X^{G T}$ is a binary variable equal to 1 when the microturbine is in operation. A similar relation is used to evaluate the primary power of the microturbine. Other constraints for the microturbine are:

$$
\begin{gathered}
X_{k, t, d}^{G T} \leq Y_{k}^{G T} \\
W^{\mathrm{GT} \_ \text {min }}{ }_{d} \cdot X_{k, t, d}^{\mathrm{GT}} \leq W_{k, t, d}^{\mathrm{GT}} \leq W^{\mathrm{GT} \_ \text {max }}{ }_{d} \cdot X_{k, t, d}^{\mathrm{GT}}
\end{gathered}
$$

where in (6) $Y^{G T}$ is a binary variable equal to 1 when the $k$-th microturbine is installed, whereas in (7) minimum and maximum operating limits are considered.

The annual total cost of the microgrid, given by the sum of capital and maintenance costs (of PV, AC, GT, ES) and net operating costs, is considered as the objective function of the MILP model. In particular, the net operating costs are calculated as the difference between the gross operating costs (natural gas for microturbines, electricity bought from the national grid, thermal energy withdrawn from the internal DHN) and the revenues, these last equal to the sum between the revenue related to electricity injected into the national grid and the distribution grid of the factory and the revenue from "white certificates" recognized to high efficiency cogeneration microturbines in accordance to the Italian legislation.

\section{Economic and environmental analysis}

Firstly, some information regarding input data and assumptions is reported in the following for each technology considered within the AEN-MGD tool.

AE T100 microturbines are characterized by a rated electrical power of $100 \mathrm{~kW}$ (ISO conditions) and a nominal electrical efficiency equal to $30 \%$. The constraints of the optimization model take into account the dependency of electrical power on ambient temperature through performance curves provided by Ansaldo Energia company. Moreover, as is shown in (5), the coefficients $\lambda_{d}$ and $\tau_{d}$, used to correlate thermal and electrical power, depend on the considered typical day $d$, that is on ambient temperature. As is highlighted in (7), the electrical power of microturbines is limited by an upper bound

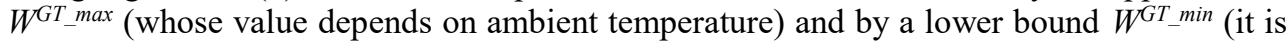
not convenient, from the efficiency point of view, to operate microturbines at low load);

Absorption chillers are of water/lithium bromide single-effect type and characterized by rated values of cooling power and COP respectively equal to $105 \mathrm{~kW}$ and 0.7 .

Each polycrystalline PV panel has a peak power of $252 \mathrm{~W}$ and a surface of $1.84 \mathrm{~m}^{2}$. Both the efficiency of the PV plant and solar radiation data depend on the considered typical day $d$ while the maximum number of PV panels which can be installed is equal to 1330; PV panels are south-oriented with tilt angle equal to $30^{\circ}$. Solar radiation has been estimated using PV-GIS tool [14] whereas efficiency values have been provided by the manufacturer of panels. 
The electrical storage system is made of lithium-ion batteries, each one having a rated capacity of $1.67 \mathrm{kWh}$. Charging and discharging efficiency values have been assumed equal to $90 \%$ whereas the maximum number of batteries to be installed has been considered equal to 130, taking into account the available space for their installation.

In Tab. 2 the main results of the AEN-MGD application to the Ansaldo Energia site are reported referring to three different possible configurations of the microgrid:

- Case 1: possible installation of AE T100s, PV, ACs, ES; electrical, thermal and cooling users of Fegino area; DHN configuration as reported in Fig. 4 left;

- Case 2: possible installation of AE T100s, PV, ACs, ES; electrical users of Fegino area; thermal and cooling users not limited to Fegino; DHN configuration as in Fig. 4 right;

- Case 3: possible installation of only AE T100s; electrical and thermal users not limited to Fegino.

Case 1 represents the initial idea of the project, whereas Case 2 considers the increase in the set of thermal and cooling users in order to exploit the thermal energy surplus production of microturbines highlighted and wasted in Case 1. Indeed, acting on a new three-way valve that could be installed in the Fegino DHN at the outlet of the hydraulic separator connected to microturbines (see Fig. 4 right), excess hot water produced by microturbines can be sent outside Fegino area to provide thermal energy to the Campi 1 absorption chiller.

Table 2. Optimal results for different microgrid configurations

\begin{tabular}{|c|c|c|c|}
\hline & Case 1 & Case 2 & Case 3 \\
\hline No. of AE T100s & 5 & 5 & 5 \\
\hline Electrical/thermal energy production of AE T100s [MWh/year] & $3927 / 6013$ & $4090 / 6287$ & $4090 / 6287$ \\
\hline Thermal energy production of AE T100s injected into DHN [MWh/year] & 0 & 2982 & 3245 \\
\hline Primary energy consumption of AE T100s [MWh/year] & 13482 & 14063 & 14063 \\
\hline Electrical Storage size $[\mathrm{kWh}] /$ No. of lithium-ion batteries & $84 / 50$ & $84 / 50$ & $0 / 0$ \\
\hline Overall PV plant size $[\mathrm{kWp}] /$ No. of PV panels & $335 / 1330$ & $335 / 1330$ & $0 / 0$ \\
\hline Electrical energy produced by PV plant [MWh/year] & 492 & 492 & 0 \\
\hline Thermal energy from DHN for thermal/cooling demand [MWh/year] & $3747 / 0$ & $3748 / 0$ & $3748 / 0$ \\
\hline
\end{tabular}
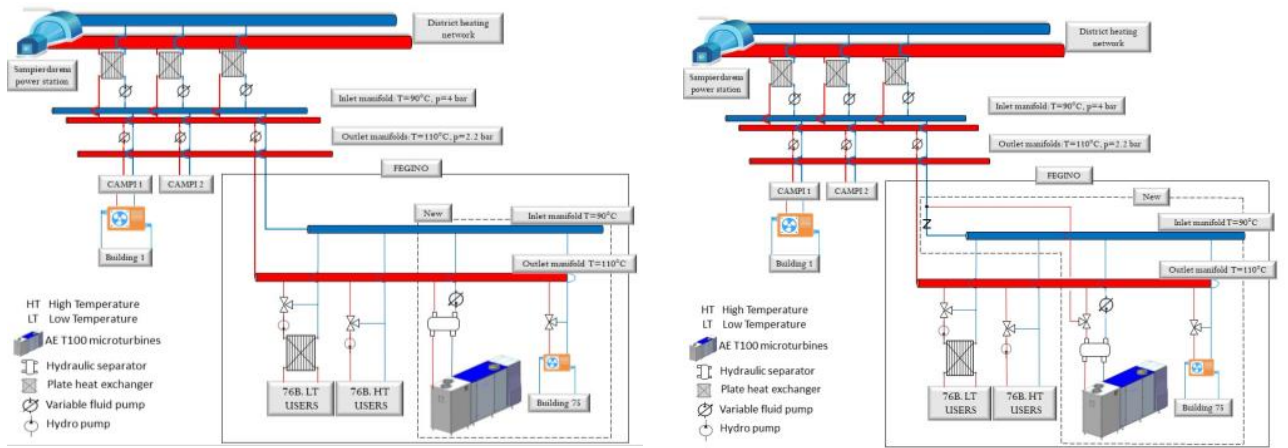

Fig. 4. DHN configuration for Case 1 (left) and Case 2 (right).

From the economic point of view, the three cases have been evaluated in terms of Net Present Value (NPV), Pay Back Period (PBP) and Internal Rate of Return (IRR). In Tab. 3 the values of the economic indicators are shown, together with the $\mathrm{CO}_{2}$ emission evaluation reported with both absolute values and percentage reductions, these last with respect to the 
current operation of the site. Finally, in Fig. 5 the optimal scheduling of the microgrid is reported referring to the typical day representing a warm spring weekday. In particular, in Fig. 5 positive bars indicate generation profiles, while negative bars indicate load profiles.

Table 3. Economic and environmental indicators

\begin{tabular}{|c|c|c|c|}
\hline & Case 1 & Case 2 & Case 3 \\
\hline NPV [€] & 1053684 & 2957010 & 3222286 \\
\hline PBP [years] & 8.0 & 4.6 & 2.7 \\
\hline IRR [\%] & $15 \%$ & $26 \%$ & $42 \%$ \\
\hline Emissions $\left[\mathrm{tCO}_{2} /\right.$ year] & $5434(-8 \%)$ & $3753(-37 \%)$ & $3762(-36 \%)$ \\
\hline
\end{tabular}
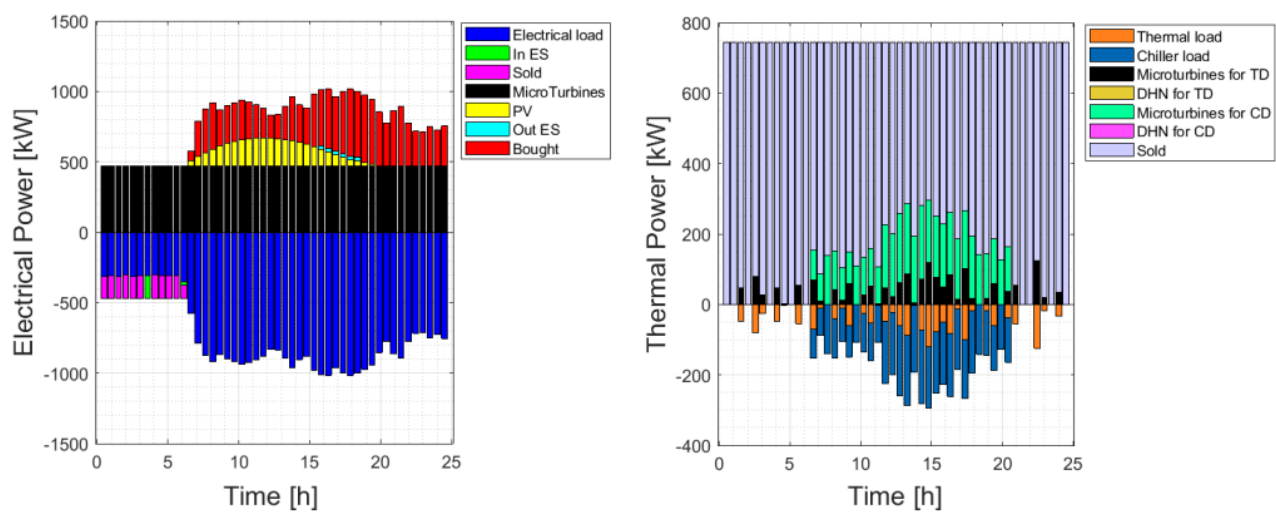

Fig. 5. Electrical and thermal balance of warm spring weekday for Case 2.

As shown in Fig. 5, the electrical balance (left graph) is characterized by:

- AE T100s electrical energy generation (black bars) which balances the electrical base load;

- limited PV production (yellow bars), mainly due to the low area available for the installation of panels;

- $\quad$ peaks of electric power demand mainly balanced by electric power from the national grid (red bars);

- electrical energy generation surplus which is mainly injected into the electric distribution grid of the factory (purple bars);

- storage system mainly used to decrease the amount of electricity bought from the national grid (light blue bars).

On the other hand, the thermal balance (right graph) shows that in warm spring weekdays the thermal load is fully satisfied by microturbines and there is a surplus production which is used to feed the Campi 1 absorption chiller.

\section{Sensitivity analysis}

A sensitivity analysis has been carried out on economic indicators (NPV, PBP, IRR) assuming $\mathrm{a} \pm 20 \%$ variation of technology capital costs, which have been assumed considering real commercial prices. As reported in Tab.4 and Tab.5, the variation of capital costs has a huge impact on economic results.

Table 4. Economic indicators with increased capital costs

\begin{tabular}{|c|c|c|c|}
\hline & Case 1 & Case 2 & Case 3 \\
\hline NPV $[€]$ & 683798 & 2587124 & 3022285 \\
\hline
\end{tabular}




\begin{tabular}{|c|c|c|c|}
\hline PBP [years] & 13.0 & 5.6 & 3.3 \\
\hline IRR [\%] & $12 \%$ & $22 \%$ & $36 \%$ \\
\hline
\end{tabular}

Table 5. Economic indicators with decreased capital costs

\begin{tabular}{|c|c|c|c|}
\hline & Case 1 & Case 2 & Case 3 \\
\hline NPV [€] & 1423570 & 3326896 & 3422285 \\
\hline PBP [years] & 6.1 & 3.6 & 2.1 \\
\hline IRR [\%] & $19 \%$ & $33 \%$ & $52 \%$ \\
\hline
\end{tabular}

Even if the economic indicators are highly affected by the technology capital cost variation, the AEN-MGD tool finds the same optimal configuration of the microgrid (in terms of number of microturbines, PV panels, etc.) which is already reported in Tab. 2.

\section{Conclusions}

In the present paper, the optimal design of a microgrid for an industrial area is proposed. The application of the developed optimization model to the Ansaldo Energia site proves that microturbines are cost-effective technologies when operated in cogeneration and trigeneration mode and their integration in microgrids with solar power plants and storage systems determines considerable primary energy savings and carbon dioxide emission reductions.

\section{References}

1. ENEA, Energy Efficiency Annual Report, 2018.

2. S.T. Blake, D.T.J. O'Sullivan, Optimization of distributed energy resources in an industrial microgrid, Procedia CIRP 67 104-109 (2018).

3. A. Hirsch, Y. Parag, J. Guerrero, Microgrids: a review of technologies, key drivers, and outstanding issues, Renewable Sustainable Energy Rev. 90 402-411 (2018).

4. E. Hossain, E. Kabalci, R. Bayindir, R. Perez, Microgrid testbeds around the world: state of art, Energy Convers. Manag. 86 132-153 (2014).

5. M. Soshinskaya, W. Crijns-Graus, J.M. Guerrero, J.C. Vasquez, Microgrids: Experiences, barriers and success factors, Renewable Sustainable Energy Rev. 40 659-672 (2014).

6. M. Karmellos, G. Mavrotas, Multi-objective optimization and comparison framework for the design of Distributed Energy Systems, Energy Convers. Manag. 180 473-495 (2019).

7. R.H. Lasseter, J.H. Eto, B. Schenkman, J. Stevens, H. Vollkommer, et al., CERTS Microgrid Laboratory Test Bed, IEEE Trans. on Power Delivery, 26 325-332 (2011).

8. R. Bayindir, E. Bekiroglu, E. Hossain, E. Kabalci, Microgrid Facility at European Union, In Proc. of ICRERA 2014, Milwaukee, WI, USA, 2014.

9. S. Bracco, F. Delfino, P. Laiolo, M. Rossi, The Smart City Energy Infrastructures at the Savona Campus of the University of Genoa, In Proc. of 2016 AEIT Int. Ann. Conf., Capri, Italy, 2016.

10. C. Gamarra, J.M. Guerrero, Computational optimization techniques applied to microgrids planning: a review, Renewable Sustainable Energy Rev. 48 413-424 (2015).

11. https://infostat.bancaditalia.it

12. https://ec.europa.eu/eurostat/statistics-explained/index.php/Main_Page.

13. International Renewable Energy Agency (IRENA), https://www.irena.org//media/Files/IRENA/Agency/Publication/2017/Oct/IRENA_Electricity_Storage_Costs_2017.pdf

14. PV-GIS tool, http://re.jrc.ec.europa.eu/pvgis/apps4/pvest.php. 